\title{
O LABORATÓRIO DIDÁTICO DE QUÍMICA: UMA MICRONARRATIVA ETNOGRÁFICA PELA ÓTICA DO CONCEITO DE ARTICULAÇÃO
}

\author{
The Chemistry didactic laboratory: a ethnographic \\ micronarrative through the articulation concept view
}

Moisés Alves de Oliveira ${ }^{1}$

\begin{abstract}
Resumo: Este artigo é parte de um estudo etnográfico de dois anos, em que foram estudados os movimentos enunciativos da ciência em um laboratório de Química do Ensino Médio no Colégio São José, São Leopoldo, RS. O intuito principal é apresentar uma microanálise de eventos de laboratório, visando contribuir para o entendimento de como é produzida a idéia de "natureza" das coisas em jogos de convencimento, contatos e relações. Para a costura teórica dos dados observados foi utilizado, em especial, o conceito de articulação, segundo a ótica dos Estudos Culturais da Ciência e tendo como foco duas questões adjuvantes: como os atuantes se estabelecem e se reconhecem dentro de um laboratório didático de ciências? E como, no laboratório, articula-se um conjunto de enunciados que lhe é particular e, por assim dizer, "natural"? O estudo, embora, preliminar, permitiu lançar alguns olhares acerca da atividade prática do laboratório escolar e especular um discurso de superação do entendimento daqueles eventos como meramente reprodutores de ideologias e de conhecimentos tácitos da uma ciência exógena.
\end{abstract}

Palavras-chave: Articulação. Laboratório didático de Química. Etnografia.

\begin{abstract}
This article is part of a two-year ethnographic study, in which the science instruction in a secondary education chemistry laboratory was studied in "Colégio São José", São Leopoldo, State of Rio Grande do Sul. The main purpose of this text is to show a microanalysis of laboratory events, aiming to contribute to the understanding of how the persuasion games, contacts and relations create the idea of a "nature" of things. In order to link the observed data theoretically, the articulation concept was used, according to the Cultural Studies of Science, focusing on two questions: How the activities are established and recognized in a science teaching laboratory? And how a proper and "natural" set of instructions are articulated in the laboratory? The study, although preliminary, enabled us to shed some light on practical activity in the school laboratory and to suggest a discourse for overcoming the understanding of those events as merely reproducers of ideologies and tacit knowledge of external science.
\end{abstract}

Key words: Articulation. Didactic laboratory of Chemistry. Ethnography.

${ }^{1}$ Doutor em Educação; docente, Departamento de Química, Programa de Pós-Graduação em Ensino de Ciências e Educação Matemática, Universidade Estadual de Londrina. Londrina, PR. <moises@uel.br>

Departamento de Química, Campus Universitário UEL

Caixa Postal 6001

Londrina, Paraná

$86.051-990$

101

Ciência \&̊ Educação, v. 14, n. 1, p. 101-114, 2008 


\section{Considerações iniciais}

Este artigo tem como objetivo contribuir para problematizar uma questão central no entendimento da produção da ciência nos laboratórios didáticos do Ensino Médio: a natureza dos conhecimentos científicos. O estudo baseou-se em uma microanálise acerca da produção da ciência de laboratório escolar, valendo-se dos modos da etnografia e dos Estudos Culturais da Ciência, dado que são relativamente recentes e restritos a alguns grupos e ainda não produziram um corpus experimental e teórico suficientemente denso para ser tomado como balizador de idéias e movimentos coletivos nas instituições de ensino do país (ACEVEDO et al., 2005; WORTMANN e VEIGA-NETO, 2001). Mesmo que se notem modificações nos focos teóricos de análise da temática em torno da ciência e da tecnologia desde a década de 1980, aproximando-se hoje das concepções histórico-culturais, as pesquisas e ações de grupos ligados ao ensino de ciências pautam-se preferencialmente pelas influências que articulam a educação, a ciência e a tecnologia pelas lentes da epistemologia do conhecimento, como uma bandeira relativamente consensual de buscar a "melhoria da qualidade do ensino" de ciências (GURGEL, 2002).

Não cabe, neste texto, uma discussão da complexa organização cultural brasileira em torno do sucesso dos modelos liberais para a educação (LIBÂNEO, 1994). Mas parece, a título de introdução ao problema do texto, dizer do quanto a corrente de pensamento em torno das idéias de Auguste Comte contribuem para supor resolvido o problema da formação do mundo natural. É interessante notar a vantagem considerável que leva a ciência - ou a crença no pensamento científico - sobre outras formas culturais, ao se apropriar do discurso e das ferramentas capazes de dar as "provas" de que tudo o que nos une possui uma natureza "natural" e que tudo o que nos separa nunca diz respeito à essência das coisas, mas, somente, a seus aspectos "meramente" políticos e culturais. Ou seja, ligados às idéias superficiais, crenças, representações mais ou menos falaciosas que criaram-se e que, em última análise, carecem de explicação científica.

Dessa idéia de "prova" científica surge a pergunta balizadora deste texto: Quais mecanismos fazem com que aqueles que podem se apropriar do "discurso" científico se apropriem também da possibilidade de definir a "natureza" das coisas? Essa pergunta, embora demasiado ampla, é um ponto de partida para a busca do entendimento do jogo enunciativo que articula o poderoso arsenal da "razão da ciência". Quanto mais essa "razão" se desenvolve, como diz Latour (1998, p. 5), “[...] mais a humanidade sucumbirá ao acordo. A religião da ciência de meu compatriota Auguste Comte (1798-1857), que conheceu no Brasil avatares tão curiosos, não tinha outro credo". Todavia, segundo as contribuições dos Estudos Culturais da Ciência, não é mais possível associar a realidade exterior, a multiplicidade dos resultados científicos e a proliferação das controvérsias com a unificação, convergência e unidade. Pela ótica cultural pode-se dizer que os resultados científicos são impregnados de aspectos morais, emotivos, políticos, político-partidários... E que quase nunca se decidem apenas pelos dados científicos e, por assim dizer, "naturais" (DASCAL, 2005; DÉSAUTELS e LAROCHELLE, 2003; LATOUR, 2002, 2001, 2000, 1994; DRIVER, 1996; KNORRCETINA, 1981).

O desafio deste texto é fazer um exercício analítico que leve em conta essa abordagem cultural para buscar novos significados, novas metáforas e, quiçá, superar os limites 
existentes dos estudos das ciências somente mediante fatos já instituídos para olhar as controvérsias e interesses que, ao final, depois de resolvidos, são vistos como fatos (GRECA e FREIRE JR., 2004; LATOUR e WOOLGAR, 1997). Sua motivação moral é atravessada pelo desejo de burilar a conexão entre a crença em um pensamento positivista mais ou menos instituído na vida escolar brasileira e a possibilidade de lançar novos olhares sobre a prática da ciência na escola, para que essa ganhe em argumentos e dados de pesquisas, como implementos da fecundidade nas discussões acerca da ciência e do ensino de ciências.

\section{Considerações acerca do campo de estudo, de teorias e métodos}

Visando contribuir para o entendimento da questão que se apresenta na interface, na articulação entre o que é meramente discurso e o que é feito natural, e dar ao texto consistência narrativa fiz recortes no campo de possibilidades de observação. Optei por um dos locais de destaque no jogo de "disciplinamento" do discurso científico, em que identidade e materialidade específica se forjam nas agonísticas ${ }^{2}$ da repetição e do uso - o laboratório de Química do Colégio São José, em São Leopoldo, RS, no qual empreendi estudo por dois anos. Este texto considera eventos de uma aula experimental sobre soluções saturadas e supersaturadas, ministrada para alunos do segundo ano do Ensino Médio. Naquela oportunidade, estive em contato com atuantes ${ }^{3}$ que me permitiram estabelecer algumas costuras e compreender melhor como a articulação funcionou enquanto eles se dedicavam a executar seus fazeres, trabalhando intensamente, arregimentando aliados, utilizando instrumentos, livros, roteiros, gastando saliva, montando quebra-cabeças, buscando articulações... De resto, fazendo esforços para que seus empenhos tivessem a força de argumentos científicos.

$\mathrm{Na}$ estada no laboratório, nunca encontrei intersecções claras, articulações bem definidas, mas uma trama enunciativa bastante complicada, da qual nada pude abstrair sem um intenso trabalho de recontextualização, de costuras teóricas, recortes e ensaios. Fui percebendo que professores e alunos divagavam por pontos irrelevantes, pulavam partes inteiras de seus textos, saíam pela tangente, muitas vezes alterando deambulatoriamente suas convicções. Foi preciso deixar de lado o professor e o aluno ideais e trabalhar no laboratório com métodos que seguissem os movimentos dos eventos (WOLLACE, 2004; LATOUR e WOOLGAR, 1997; GEERTZ, 1992, 1989). É nesse contexto que entendo o que se chama, genericamente, de etnografia do campo aberto (WOLLACE, 2004) e busco, em vez de escavar alguma realidade presente em determinadas culturas, fazer uma experimentação, seguir o movimento dos próprios atuantes, valendo-me de qualquer recurso disponível para tal. Não se trata, portanto, de ser simétrico ou assimétrico no trabalho de seguir professores e alunos, mas de manter-me fiel ao que eles fazem.

\footnotetext{
${ }^{2} \mathrm{O}$ termo agonística tem papel central neste texto, é entendido como ocorrendo nas relações, parcerias, discussões e brincadeiras travadas em prol de se atingir um objetivo (LATOUR e WOOLGAR, 1997).

${ }^{3}$ Os professores, alunos e entidades não-humanas envolvidos serão tratados genericamente por "atuantes". $\mathrm{Na}$ concepção de Latour, o ator só pode ser entendido por intermédio de sua atuação, ou seja, quando outros atores da rede são modificados, perturbados ou criados pela personagem em apreço (LATOUR, 2001; SERRES, 1999; VEIGA-NETO, 1996).
} 
Oliveira, M. A.

A aceitar-se a perspectiva assimétrica, é verdade que são ignoradas as minúsculas dimensões da rede científica, supondo-se que a ciência e tecnologia se estenda por toda a parte sem custo algum, deixando de lado apenas impressionantes bolsões de irracionalidade que precisariam ser eliminados com a melhoria da educação e com uma metodologia mais apropriada. Mas na perspectiva simétrica o que se ignora de todo é exatamente a existência da rede científica, de seus recursos, de sua capacidade de, às vezes, fazer preponderar para um dos lados o equilíbrio de forças. (LATOUR, 2000, p. 320)

Ao transladar entre os atuantes e suas ações, foi menos para marcar suas independências, ou passar da objetividade à subjetividade, e mais para indicar deslocamentos, tendências, invenções de vínculos (articulações) que não existiam e que, até certo ponto, modificaram os originais: um professor, um aluno, um "etnógrafo" em posse de equipamentos e de enunciados de laboratórios está diferente!

Do ponto de vista ferramental, a metodologia seguiu as técnicas de coleta e análise apresentadas por Graue e Walch (2003), Adler e Adler (1994), Latour (1985) e Costa (2002), no que apresentam como "descrição narrativa" e da observação participante pela ênfase na idéia do "professor que pesquisa". Foram utilizados os métodos de geração de dados - por meio da tomada de notas (rascunho), gravações, fotos e entrevistas - e da produção do registro de dados, com a construção de uma narrativa utilizando alguns fragmentos do que foi observado no laboratório. O que difere dessa percepção de teoria e método é a visão cultural presente, as subjetividades, os movimentos retóricos, jogos de poder, de voz (autoridade da voz), da presença de entidades não-humanas e, sobretudo, na idéia da impossibilidade de qualquer uma das "técnicas" funcionarem de forma desvinculada dos jogos de poder que as constituem (GOTTSCHALK, 1998; CALDEIRA, 1988).

O conceito teórico empregado nesse "exercício" de entendimento é o da articulação, por permitir uma análise dos eventos por meio das linguagens que figuraram articuladas por intensas negociações. Embora outros autores tenham ajudado na compreensão do significado de articulação, procuro manter conexão com o pensamento de Latour (2001, p. 345) que a entende como a expressão que "ocupa a posição esvaziada pela dicotomia entre objeto e sujeito ou mundo exterior e mente". Em outros termos, funciona com a idéia de "falta", como sendo a mãe da própria natureza das coisas.

\section{Um exercício de "contextualização": apresentando o conceito de articulação}

Foram apresentadas acima algumas motivações e ferramentas que ajudarão a perceber quanto há de trabalho e agonísticas para que alguns atributos assumam o status de "natureza". Agora é preciso marcar alguns pontos, trazer "imagens" do que foi visto no laboratório para tentar responder como os atuantes se estabelecem e se reconhecem naquele espaço e como, ali, há um conjunto de enunciados que lhe é particular e, por assim dizer, natural. Cabe apresentar um entendimento de como a articulação será utilizada no texto. Como estou em 
busca do entendimento conceitual dos termos e sobretudo, de como estes podem funcionar como aliados engajados na busca de teorizações específicas para olhar as micropráticas do laboratório escolar, o conceito de articulação só poderá fazer sentido se costurado diretamente com os eventos do campo e se dessa costura emergir uma "versão" específica de articulação (GROSSBERG, 1996). É este o exercício que passo a fazer.

Vejamos um excerto da aula experimental de laboratório, trecho I, sem adiantar muitos detalhes de falas dos atuantes, que versavam acerca de solubilidade de determinada solução: "[...] Não! Vocês não sabem, por que vocês não sabem o grau de solubilidade a 80! Ela pode ser, dependendo do grau de solubilidade, diluida, concentrada [...]".

Nesse esboço há proposições que enunciam um conteúdo específico: solubilidade, grau, a 80, que já dizem algo acerca de um campo. Os símbolos lingüísticos, o número, podem funcionar como uma articulação enunciativa. Derrida (1999, p. 280) diz que "A linguagem distingue as nações entre si; só se sabe de onde é um homem depois de ele ter falado". Esta é uma expressão que tem sentido para o que é apresentado aqui, quando se pensa acerca de alguns esboços de fala ao remeterem a um conjunto amplo de representações, ao mesmo tempo em que estabelecem uma imagem identitária. Há, portanto, algo entre um enunciado e uma representação.

Vamos a um segundo trecho (trecho II), em que o trecho I está subentendido:

Prof. Isadora ${ }^{4}$ - "Não! Vocês não sabem! por que vocês não sabem o gran de solubilidade do [ $\mathrm{Na}_{2} \mathrm{SO}_{3} 5 \mathrm{H}_{2} \mathrm{O}$ tiosulfato de sódio] a 80! Pode ser, dependendo do gran de solubilidade, diluída, concentrada [...]" [Já dissolveu tudo?].

A interrogação assertiva “Já dissolveu tudo?", suprimida no trecho I, pode implicar uma mudança importante de representações possíveis. Se no trecho I há uma tendência a considerar um evento em que a atividade prática de laboratório não esteja presente, no trecho II isso já é bastante plausível. Agora, alguém articula um conjunto discursivo que possibilita imaginar a dissolução de uma substância Química, o tiossulfato de sódio. O conjunto: letra-números "a 80 ", embora não apresente explicitamente a unidade ${ }^{\circ} \mathrm{C}$, que lhe confere "identidade" específica, já tem articulação maior com a dissolução e temperatura.

Esta descrição é um tanto astuciosa, conquanto já "contaminada" pelo próprio contexto do artigo. Mas não é um jogo de esconde-esconde: é, apenas, uma estratégia para apresentar como a articulação possibilita, por um número reduzido de proposições (palavras, números e letras combinadas com números), ser representação de muitas possibilidades - a articulação é o efeito de multiplicar possibilidades. Graças a ela, a linguagem pode dar conta de enunciar vários sentidos possíveis que, de outra forma, ficariam dispersos. Assim, a linguagem surge da própria dispersão ou de uma necessidade cada vez maior e mais complexa de comunicação (DERRIDA, 1999). A articulação pode, então, criar uma unidade específica de

\footnotetext{
${ }^{4}$ Os nomes apresentados são fictícios.
} 
Oliveira, M. A.

linguagem que, ao mesmo tempo, distingue a pessoa que está em um laboratório escolar de Química e produz a "definição" do próprio laboratório, a partir de diferentes elementos humanos ou não-humanos - e dependendo das condições e necessidades, não necessariamente essenciais umas às outras.

Numa frase, e num só movimento, podem-se marcar relações de tempo, de conseqüência, de possessão, de localização, que entram realmente na série sujeito-verbo-atributo, mas não podem ser demarcadas por uma distinção tão vasta. (FOUCAULT, 1999, p. 136)

Em um movimento, em uma imagem, podem-se articular elementos de referência que se apóiam mutuamente. Este é o estatuto do laboratório e é nesse ponto que Latour dá contribuições importantes. Ao invés de ser intermediária,

ao invés de constituir um privilégio da mente humana cercada de coisas mudas, a articulação se torna uma propriedade bastante comum das proposições, da qual diversos tipos de entidades podem participar. Embora utilizado em lingüística, o termo articulação de forma alguma se limita a linguagem e pode ser aplicado não apenas a palavras como também a gestos, artigos, cenários, instrumentos, localidades, testes. (LATOUR, 2001, p. 165, grifo do autor)

Latour (2001, p. 345) diz que "a articulação não é uma propriedade da fala humana, mas uma propriedade ontológica do universo", vascularizando-se pela rede de relações sem que haja um indivíduo, ou coisa, detentor da articulação. "A questão não é mais saber se as assertivas se referem ou não a um estado de coisas, mas apenas se as proposições são ou não bem-articuladas"(p. 345, grifo meu). Ele relaciona as proposições ao conceito de translação, que dentro dos Estudos de Ciências, tem sua ênfase na prática dos atuantes, multiplicando-se os termos intermediários que existem nas transformações típicas das ciências como inscrição, articulação ou translação (LATOUR, 1995). Em suas conotações lingüística e material, Latour entende a translação como desdobramentos por entre outros atores, cuja mediação é indispensável à ocorrência de qualquer ação. Em lugar de uma oposição rígida entre contexto e conteúdo, as cadeias de translação referem-se ao trabalho de articulação graças ao qual os atores modificam, deslocam e transladam seus vários e contraditórios interesses (LATOUR, 2001).

\section{A articulação: o caso da solução supersaturada de tiossulfato de sódio}

Inspirado na argumentação acima, em que ensaio uma costura do conceito de articulação ao próprio evento, trago mais um excerto do diário de campo, parte de uma aula prática preparada pela professora laboratorista "Rosalyn" e ministrada aos alunos do $2^{\circ}$ ano do Ensino Médio, turma B, pela professora "Isadora". O objetivo era que cada grupo de alunos preparasse uma solução supersaturada de $\mathrm{Na}_{2} \mathrm{SO}_{3} 5 \mathrm{H}_{2} \mathrm{O}$ (tiossulfato de sódio), por 
meio de dissolução e resfriamento. Em dado momento dos procedimentos experimentais surgiu a seguinte conversa em relação a como representar as observações feitas diretamente no tubo de ensaio:

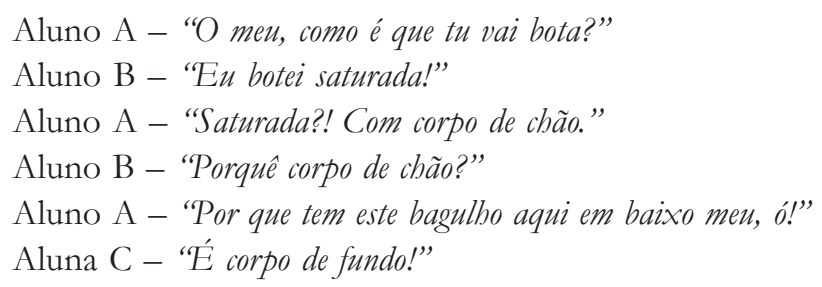

Há "algo" no fundo do tubo de ensaio que desencadeia uma agonística entre os alunos. A preocupação dos alunos e a informação da aluna C "É corpo de fundo", como um enunciado que se articulava com a aula teórica de que todos participaram, tinham a validação que se vascularizava nos livros, na voz da professora e nas informações acerca do coeficiente de solubilidade do tiossulfato de sódio em outras discussões...

Porém, nenhum desses recursos discursivos poderia dissolver-se ou recristalizar-se na frente deles. Aproveitando o pensamento de Latour (2001), os vocábulos dissolver-se, recristalizar-se, não dissolvem, não recristalizam dentro de um tubo de ensaio que, por sua vez, está dentro de um béquer, sobre uma tela de amianto, disposta sobre um tripé e, por baixo de tudo, queima-se o butano (Figura $1^{5}$ ).

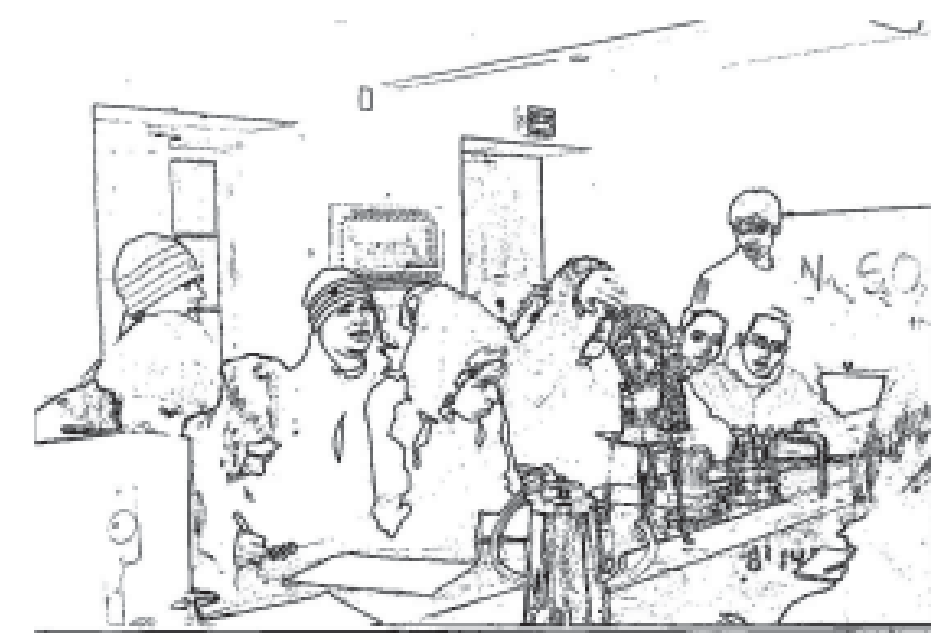

Figura 1. Aula prática: preparação de uma solução supersaturada. Aluno B manipula um termômetro em frente ao equipamento de dissolução. Turma $2^{\circ} \mathrm{B}$, Ensino Médio.

\footnotetext{
${ }^{5}$ A figura 1 é uma foto tirada durante o período da pesquisa e depois tratada para ter o aspecto de desenho, que parece suspender a linearidade, deixando mais espaço para os intermediários, para a imaginação, e protege a "identidade" dos atuantes.
} 
Cada uma dessas entidades - é prudente lembrar - é conseqüência de longos trajetos de estudos, controvérsias e trabalhos... e agora são incorporadas à rotina de um laboratório de Ensino Médio que funciona em meio a muitas conversas, brincadeiras, dúvidas, assertivas, riscos de queimadura, de intoxicação...

Prof. Isadora - "Então em vou pesar o sal que é o tiossulfato de sódio, vou dar para vocês dentro do tubo de ensaio, vocês vão colocar água, conforme o roteiro comenta, e vocês vão aquecer neste copo de béquer, que eu já coloquei ali para vocês, [...], não ponbam o nariz de vocês para aspirar!" Aluno Z - "Ele é tóchico?"

Prof. Isadora - "Ele é tóxico, então vocês tomem cuidado para não ficar ali aspirando!"

Alunos - [brincando com o anterior] "tóchico? É assim que fala meu!" [comentam sobre a toxicidade].

Enquanto alguns se interessam pelo "bagulho" que agora lentamente começa a se dissolver, por si só, outros se entretêm. À esquerda, pude observar uma aluna escrevendo seu nome na bancada, desinteressada pela aula, pelas discussões... parecia estar em outro lugar.

Seguindo a análise da ilustração, vê-se um texto, ao mesmo tempo presente e ausente, implexo na cenografia. No canto à direita, em letras gigantes, figura, no quadro, a fórmula do tiossulfato de sódio. Mas ela não esteve sempre ali, foi produzida pela falta de informação.

Aluna D - "Pssora... pssora... [A professora não ouvia, por isso gritou] PSSORAAAAAA! [...] a fórmula do tiossulfato é, só, é... N-A-2-S-2-Ó-3?’”

Prof. Isadora - "Não! Quem vai escrever no quadro a fórmula do tiossulfato?"

Aluna D - "Eu vou pssora!"

Ao fundo, um outro atuante (não-humano): a tabela periódica. Ela figura como um diploma, um tributo à capacidade de articulação dos químicos, numa longa genealogia que passa por Dimitri Mendeleiev (VIDAL, 1986), interessantemente posto próximo à porta, como que entrando ou saindo do laboratório, como que longe no tempo e no espaço ao mesmo tempo que presente e rearticulável em suas partes, desmembrável em múltiplos níveis e formas enunciativas. Foi da tabela periódica que saíram, por intermédio de uma aluna, as letras que agora figuram, rearticuladas, no quadro, formando não uma nova tabela, mas um novo código de referência, que permite transladar da tabela à aula teórica, e passa a dar sentido aos cristais - meio esbranquiçados dentro dos tubos de ensaio -, que alguns olham atentamente, enquanto se autotransformam em líquido e vão transformando os alunos que os manipulam.

A tabela periódica, o quadro, a aluna, as teorias, o tiossulfato de sódio (bagulho), o laboratório, como diz Stuart Hall (GROSSBERG, 1996, p. 141), "não são necessários, tampouco essenciais uns aos outros, e a todo momento". É nisso que a idéia de articulação traz importantes contribuições à pesquisa de campo. Por sorte eu pude estar lá, em tempo de perceber que as linhas que fazem uma profusão de sentidos, de palavras, de proposições constituem um sistema representativo e determinado e, por assim dizer, específico, no momento em que circunstâncias, conexões e referências estão sendo forjadas e postas a circular, juntas, para logo se dissipar e deixar um rastro que ora cintila ora se apaga. No momento em 
que começa a ganhar mais aliados um enunciado torna-se mais científico, mais raro, menos cotidiano e mais laboratorial. Quando os alunos vão se alinhando aos conceitos (Aluno A - "O meu, como é que tu vai bota?" Aluno B - "Eu botei saturada!" Aluno A - "Saturada?! Com corpo de chão") e ajustando suas faltas a um discurso validado que lhes dê "sustentação" (Aluna C - "É corpo de fundo!") , ele passa a ser mais aceito como autônomo e passível de ser utilizado numa rede específica de discurso (VEIGA-NETO, 2003, p. 114). Vejamos mais um exemplo:

Polifonias - "Ô cheiro bom de fogo meu, [...] ô meu, tem que ficar quanto [...] até dissolver [...] 40 graus, ta 40 graus? O que que acontecen a 40 graus ai meu? [...] A quarenta gramununss? [...] Ai ó, ta acontecendo alguma coisa com o sólido ali ó, ele dissolven um ponco cara, ta dissolvendo, ta dissolvendo, ó ali meu, óbóó! Tem que dissolver tudo. Ó tem que ver a temperatura né? Ô pssora será que já dá para dizer que deu uma dissolvidinha a 40 graus? Olha aí, já deu um dissolvidinba! [olham demoradamente] Óhóó! [...] Ô pssora, como é que a gente vai saber qual é a temperatura certa que dissolve? Se ai tem um monte? Todos são iguais [...]”

$[\ldots]$

Aluno B - "Pô men é tri, ele dissolven tudo!"

A versatilidade da articulação começa a fazer sentido para o que se almeja neste texto. Num instante pulveriza-se, apaga-se todo o trabalho da professora Rosalyn para preparar a prática, apaga-se o arsenal de instrumentos necessários para fazer o tiossulfato de sódio se dissolver, esquece-se da professora Isadora, prostrada em frente à balança durante quase toda a aula, na luta por fazer passar os cristais através do funil para dentro do tubo de ensaio, conforme indicado no manual.

Por um instante, os atuantes humanos se ocultam para que o tiossulfato de sódio emirja e realize, por si mesmo - como dotado de uma propriedade inata, a dissolução: "ele dissolveu um pouco cara, ta dissolvendo! Ta dissolvendo!'. As conexões necessárias passam a não deter uma origem, algo isolado ou fixo, e a representar uma idéia, um gesto, alguém que passa. $\mathrm{O}$ caráter de manipulação humana oculta-se e, "entretanto, se mantém para permitir analisar ou compor as mais complexas representações [...] há sempre uma nomeação adormecida, uma forma que guarda fechado entre suas paredes sonoras o reflexo de uma representação invisível e todavia inapagável" (FOUCAULT, 1999, p. 145).

Ora, sem o manual, sem uma longa trajetória de acúmulo de conhecimentos, de controvérsias, sem os instrumentos, nenhum tiossulfato de sódio estaria ali se dissolvendo. Mas, logo tudo se altera, "Ô pssora será que já dá para dizer que deu uma dissolvidinha a 40 graus? [...] Como é que a gente vai saber qual é a temperatura certa que dissolve?’. Nessa passagem, de novo há a intenção de manipulação para que ocorra a dissolução. Reaparece a figura da professora e os observadores passivos de um fenômeno natural voltam a manipular o experimento, querem controlar a temperatura, especulam a exatidão da teoria, "Como é que a gente vai saber [...]", expõem o tiossulfato de sódio a um interrogatório acerca de sua identidade de dissolução... De repente, todos voltam a olhar para dentro de béquer com água desprendendo bolhas, olham atentamente os últimos vestígios de sólidos se dissolverem e confundirem com a água: "Pô meu é tri, ele dissolveu tudo?".

Pode-se perguntar: quem estava praticando a ação neste experimento? Os alunos, sustentados por um grande arsenal, posto por trás (OLIVEIRA, 2006), ao aquecerem o 
tiossulfato... ou, o tiossulfato, ao dissolver-se na frente de seus olhos? Para Latour (2001), esta pergunta tem pouco sentido, já que a construção do conceito de dissolução, a independência do tiossulfato ao se dissolver, como dotado dessa propriedade intrínseca, e a capacidade de os alunos manipularem estes eventos devem ser tomadas como movimentos e não como mera recombinação de elementos preexistentes. No movimento de articulação, tanto os alunos quanto o tiossulfato de sódio "intercambiaram” e, mutuamente, aprimoraram suas propriedades. Os alunos ajudaram o tiossulfato a ganhar ainda mais realidade e o tiossulfato ajudou os alunos a ganharem (re)conhecimento e... uns pontinhos na média final. Mas, é importante destacar, apenas quando tudo corre bem é possível dizer sobre o movimento de fortalecimento mútuo. Caso as coisas tivessem dado errado e uma agonística surgisse, cada um estaria novamente separado e tomando posições distintas, como vimos várias vezes acontecer, microscopicamente, nos pequenos trechos apresentados ao longo deste artigo.

\section{Considerações finais}

Neste momento talvez seja possível dizer, timidamente, o que penso ser uma contribuição importante de Bruno Latour para o campo das pesquisas - agora também na escola acerca da produção das ciências.

Por mais artificial que seja o cenário, uma coisa nova, independente desse cenário, tem que surgir para que o empreendimento todo não haja sido em vão. É em virtude dessa "dialética" entre fato e artefato [...][que] torna-se de todo impossível aceitar um argumento puramente construtivista [...] Boa parte da filosofia da ciência, desde Hume e Kant, consiste em assumir, repelir, obstruir, retomar, abjurar, resolver, refutar, embrulhar e desembrulhar esta antinomia impossível: de um lado, os fatos são construídos experimentalmente, jamais escapando a seus cenários artificiais; de outro, é imperioso que os fatos não sejam construídos e que apareça alguma coisa não-artificial [...] como é ao mesmo tempo fabricado e não-fabricado, no experimento há sempre mais do que nele foi posto. Explicar o resultado de um experimento mediante uma lista de fatores e atores estáveis sempre apresentará, pois, um déficit. (LATOUR, 2001, p. 146, ênfases e adição do autor)

As contribuições de Latour são importantes por duas razões: a primeira, por dar um golpe certeiro naqueles que acreditam ser a ciência experimental escolar um jogo zerado, em que entram ideologias, conteúdos ... e saem ideologias, conteúdos ... A segunda, com mais

utilidade para quem tem afinidades com o laboratório, é de incluir nas teorizações, de maneira simétrica, as entidades não-humanas, imprescindíveis à existência delas mesmas e dos humanos nas teorizações em que possíveis referências podem ou não fazer com que seus trabalhos apóiem-se mutuamente, dependendo de como estão articuladas. "Ao invés de construir um privilégio da mente humana cercada de coisas mudas, a articulação se torna uma propriedade 
bastante comum das proposições, da qual diversos tipos de entidades podem participar" (LATOUR 2001, p. 165).

As proposições articuladas parecem fazer sentido para que se possa entender o efeito multiplicador dos eventos. Pensando por assertivas teríamos alunos executando uma prática em que observam a solubilidade do tiossulfato de sódio em um experimento pra lá de manjado e depois anotam os resultados e produzem relatórios. Acreditar nisso é encerrar a discussão por aqui e procurar outro assunto para pesquisa. Mas, se pensarmos que para aquele experimento ter sucesso foram necessários investimentos em laboratório, em professores, equipamentos - simples, se comparados a outros laboratórios, mas importantes para aquelas pessoas -, ou que alunos irão, depois, disputar vestibulares tomando aquelas informações como válidas, que a vida de um aluno que um dia passou pela escola e pelo laboratório pode tomar rumos diversos das dos que nunca puderam freqüentá-los, teremos muitas outras proposições a fazer. Simon (1995) contribui nesse sentido ao utilizar a articulação como possibilidade para discutir as práticas que podem ocorrer entre a escola e o trabalho de outras pessoas em diversos locais de produção cultural. Toma articulação na acepção de conexões de um trabalho em específico com uma variedade de locais em que noções de conhecimento, de verdade e de desejo estão sendo produzidas e diz o que isso pode significar em relação a possibilidades de futuras cooperações e alianças.

Ao tentar tornar aparente uma articulação particular entre variadas práticas de trabalho cultural, estou tentando tornar visível um novo arranjo, vínculo ou conexão particular entre pessoas cujos compromissos primários de trabalho se situam numa variedade de locais de produção semiótica. (SIMON, 1995, p. 66)

A isso acrescento que o conteúdo acerca de saturação e cristalização fica ainda mais forte dentro do contexto da ciência escolar, que o tiossulfato tornou-se mais conhecido dos alunos pela manipulação que fizeram e por isso, cada vez mais, ganha independência como substância. Há, portanto, uma rede que funciona para que um enunciado ganhe força, mas por vezes não está explícito. Por exemplo, se tomo um dos fios que leva até a professora Rosalyn, que dias antes preparava a prática, teremos mais um evento - pouco lembrado no momento da execução - articulado à trama. Se tomo outro exemplo e sigo o fio que leva à articulação da tabela periódica, entro num universo enorme de inscrições sobrepostas que lhe dá o status de tabela periódica dos elementos. Vejo que assim a cristalização funcionou com outros importantes, mas não necessariamente pertencentes, eventos, que se constituem em redes, nas quais todos os que nela atuam são afetados.

Isso poderia ser entendido como apoio mútuo, que autoriza os atuantes a representarem e serem representados pelo conjunto que constitui suas articulações. "Esses termos exigem um quadro prático de referência, no interior do qual se possa vislumbrar como nosso trabalho pode complementar a prática de outras pessoas" (SIMON, 1995, p. 66).

Apesar dos percalços, em parte apresentados acima, o experimento foi bem sucedido e, ao final, os alunos puderam ver os cristais de tiossulfato de sódio se refazerem dentro da solução após terem ficado um tempo em repouso. Latour (2001, p. 145) diz que, 
Oliveira, M. A.

um experimento é um texto sobre uma situação não-contextual, mais tarde avaliado por outros para se saber se é simplesmente um texto. Caso o teste final seja bem-sucedido, então não é simplesmente um texto, há na verdade uma situação real por trás dele e tanto o ator quanto seus autores ostentam nova competência.

Os alunos, as professoras, os manuais "provaram" que o tiossulfato dissolve-se e recristaliza-se por si mesmo, mas não foi uma travessia direta: alunos $\leftrightarrow$ dissolução/recristalização do tiossulfato de sódio. Graças a um número tão complexo de articulações e proposições quanto se queira ir fundo, seguir as linhas que tornaram possível a prática ocorrida no laboratório será encontrar mais linhas que levem a outros emaranhados de articulações.

\section{Conclusão}

Há muito a avançar nesta temática. Pensar articulação no sentido de que fatos e entidades se estabelecem pelo contato, pela ajuda mútua, já dá indícios de respostas à pergunta acerca dos mecanismos que possibilitam articular a natureza das coisas com as quais interagimos. É bastante estimulante, e ao mesmo tempo faz entender a idéia de que não é possível reduzir a escola e o laboratório escolar de ciências a simples reflexos. Pude perceber, nas aulas práticas que acompanhei, pouca preocupação dos alunos - ou das professoras - em não misturar as realidades do mundo com o que eles diziam dessa realidade. Elas usavam, de forma interessada, qualquer recurso que fosse possível. Aí está a riqueza, a possibilidade de olhar o laboratório escolar como politicamente ativo e capaz de suas "próprias" articulações...

\section{Referências}

ACEVEDO, J. A. et al. Mitos da didática das ciências acerca dos motivos para incluir a natureza da ciência no ensino das ciências. Ciência \& Educação, Bauru, v. 11, n. 1, p. 1-15, 2005.

ADLER, P. A.; ADLER, P. Observational techniques. In: DENZIN, N. K.; LINCOLN, Y. S. (Eds.). Handbook of qualitative research. Thousand Oaks, CA: Sage, 1994. p. 377-392.

CALDEIRA, T. P. R. A presença do autor e a pós-modernidade em antropologia. Novos Estudos, Rio de Janeiro, n. 21, p. 133-157, 1988.

COSTA, M. V. (Org.). Caminhos investigativos II: outros modos de pensar e fazer pesquisa em educação. Rio de Janeiro: DP\&A, 2002. 
O laboratório didático de Química: ...

DASCAL, M. A dialética na construção coletiva do saber científico. In: REGNER, A. C.; ROHDEN, L. (Orgs.). A filosofia e a ciência redesenham horizontes. São Leopoldo: EdUNISINOS, 2005. p. 15-32.

DERRIDA, J. Gramatologia. 2. ed. São Paulo: Perspectiva, 1999.

DÉSAUTELS, J.; LAROCHELLE, M. Educación científica: el regreso del ciudadano y de la ciudadana. Enseñanza de las Ciencias, Barcelona, v. 21, n. 1, p. 3-20, 2003.

DRIVER, R. Young people's images of science. Buckingham: Open University Press, 1996.

FOUCAULT, M. As palavras e as coisas: uma arqueologia das ciências humanas. 8. ed. São Paulo: Martins Fontes, 1999.

GEERTZ, C. Gêneros confusos. La configuración del pensamiento social. In: et al. (Orgs.). El surgimiento de la antropologia posmoderna. Barcelona: Gedisa, 1992. p. 63-78.

Estar lá, escrever aqui. Diálogo, São Paulo, n. 22, v. 3, p. 58-63, 1989.

GOTTSCHALK, S. Pós-modern sensibilities and ethnographic possibilities. In: BANKS, A.; BANKS, S. (Orgs.). Fiction and social research. London: Sage, 1998. p. 206-226.

GRAUE, M. E.; WALSH, D. J. Investigação etnográfica com crianças: teorias, métodos e ética. Lisboa: Fundação Calouste Gulbenkian, 2003.

GRECA, I. M.; FREIRE JR., O. A “crítica forte” da ciência e implicações para a educação em ciências. Ciência \& Educação, Bauru, v. 10, n. 3, p. 343-361, 2004.

GROSSBERG, L. On postmodernism and articulation: an interview with Stuart Hall. In: MORLEY, D.; CHEN, K-H. (Orgs.). Critical dialogues in cultural studies. London/ New York: Routledge, 1996. p. 112-127.

GURGEL, C. M. A. Educação para as ciências da natureza e matemáticas no Brasil: um estudo sobre os indicadores de qualidade do SPEC (1983-1997). Ciência \& Educação, Bauru, v. 8, n. 2, p. 263-276, 2002.

KNORR-CETINA, K. D. The manufacture of knowledge: an essay on the constructivist and contextual nature of science. New York: Pergamon Press, 1981.

LATOUR, B. Reflexão sobre o culto moderno dos deuses fe(i)tiches. Bauru: EDUSC, 2002.

A esperança de pandora: ensaios sobre a realidade dos estudos científicos. Bauru: EDUSC, 2001.

Ciência em ação: como seguir cientistas e engenheiros sociedade afora. São Paulo: Editora Unesp, 2000. Mais, p. 5.

A guerra das ciências. Folha de S. Paulo, São Paulo, 15 nov., 1998. Caderno 
Oliveira, M. A.

Dád-me un laboratorio y moveré el mundo. In: IRANZO, J. M. et. al. (Orgs.).

Sociologia de la ciencia y la tecnologia. Madrid: Consejo Superior de Investigaciones Científicas, 1995. p. 237-257.

Jamais fomos modernos. Rio de Janeiro: Ed. 34, 1994.

Les "vues" de l' espirit: une introduction à l'anthropologie des sciences. Culture

Technique, Paris, v. 14, p. 4-29, 1985.

.; WOOLGAR, S. A vida de laboratório: a produção dos fatos científicos. Rio de Janeiro: Relume Dumará, 1997.

LIBÂNEO, J. C. Didática. São Paulo: Cortez, 1994.

OLIVEIRA, M. A. A ciência do laboratório escolar produzindo o "por trás": análise de um experimento de química no ensino médio. In: ENCONTRO NACIONAL DE ENSINO DE QUÍMICA, 12., 2006, Campinas. CD-Rom... Campinas, 2006.

SERRES, M. Luzes: cinco entrevistas com Bruno Latour. São Paulo: Unimarco, 1999.

SIMON, R. I. A pedagogia como uma tecnologia cultural. In: SILVA, T. T. (Org.).

Alienígenas na sala de aula. Petrópolis: Vozes, 1995. p. 61-84.

VEIGA-NETO, A. J. Foucault e a educação. Belo Horizonte: Autêntica, 2003.

A perspectiva historicista da ciência e a sociologia da educação. Epistéme, Porto

Alegre, v. 1, n. 1, p. 101-113, 1996.

VIDAL, B. História da química. Lisboa: Edições 70, 1986.

WOLLACE, S. Towards a symetric (social-material) ethnography: theorizing innovation and conservation practices in health care. In: SOCIETY FOR SOCIAL STUDIES OF SCIENCE AND EUROPEAN ASSOCIATION FOR THE STUDY OF SCIENCE AND TECHNOLOGY CONFERENCE, 2004, Paris. Anais eletrônicos... Paris, 2004.

WORTMANN, M. L. C.; VEIGA-NETO, A. J. Estudos culturais da ciência e educação. Belo Horizonte: Autêntica, 2001.

Artigo recebido em abril de 2007 e aceito em novembro de 2007. 